\title{
Effects of Acylpeptide K-26 on the Motility of Sea Urchin Sperm Model. II. Mechanism of the Inhibitory Effect of K-26
}

\author{
Etsuo Yokota ${ }^{1,2}$, Issei Mabuchi', Akio Kobayashi ${ }^{3}$ and Hidemi Sato ${ }^{2}$ \\ ${ }^{1}$ Department of Biology, College of Arts and Sciences, University of Tokyo, \\ Komaba, Meguro-ku, Tokyo 153, ${ }^{2}$ Sugashima Marine Biological Laboratory, \\ Nagoya University, Toba, Mie 517 and ${ }^{3}$ Department of Agricultural Chemistry, \\ Faculty of Agriculture, Okayama University, Tsushimanaka 1-1-1, Okayama \\ 700, Japan
}

\begin{abstract}
An acylpeptide called K-26 inhibited the motility of Triton-extracted sea urchin sperm. This inhibition was canceled by the addition of both cAMP and a Triton X-100-soluble fraction of the sperm. The concentration of cAMP that was required to restore the motility was above $1 \mu \mathrm{M}$. Incorporation of Pi into the Triton-extracted sperm was suppressed by K-26 at the same concentration as that which inhibited the motility. A factor in the Triton-soluble fraction that was able to cancel the inhibition of the motility by K-26, was partially purified by hydroxylapatite and DEAE-cellulose column chromatographies. In both of these steps, the activity to cancel the inhibition of the motility coeluted with that of cAMP-dependent protein kinase (cA kinase). The activity of cA kinase was also inhibited by K-26. The incorporation of Pi into the Triton-extracted sperm was suppressed in the presence of K-26 and was restored by the addition of both cAMP and the cA kinase fraction. From these results, it was suggested that K-26 affects the cAMP-dependent phosphorylation in the Triton-extracted sperm and thereby inhibits the process to convert the sliding of outer doublet microtubules into the bending of the flagellum.
\end{abstract}

The sliding microtubule model for ciliary and flagellar movement has been well supported by a variety of experiments $(18,20)$. The production of the bending wave from the sliding movement between the outer doublet microtubules in the flagellum is thought to occur as a result of local differences in the amount of sliding along the axonemal axis (19). Little information is available as to the mechanisms responsible for regulating the dynein arm crossbridge cycling to produce and propagate the bending waves. Studies by Brokaw et al. (3), Gibbons and Gibbons (8), and Katada et al. (12) have shown that the regulation of wave form and the propagation of bending waves in Triton X-100-extracted sea urchin sperm are performed in a $\mathrm{Ca}^{2+}$ dependent manner. On the other hand, studies have also suggested that a cycle of

Abbreviations used: cAMP, adenosine 3', 5'-cyclic monophosphate; cA kinase, cAMP-dependent protein kinase; DPO, 2, 5-diphenyloxazole; DTT, dithiothreitol; EGTA, ethyleneglycol bis- $(\beta$ aminoethylether)-N, N, N', N'-tetraacetic acid; FSW, filtrated sea water; MOPS, 3-( $N$-morpholino) propanesulfonic acid; PEG, polyethylene glycol; PMSF, phenylmethylsulfonyl fluoride; POPOP, 1, 4-bis[2-(5-phenyloxazolyl)] benzene; TCA, trichloroacetic acid. 
cAMP-dependent protein phosphorylation and dephosphorylation may be an important regulator of the flagellar movement in the Triton-extracted sea urchin sperm $(4,11,16,21)$.

In the preceding paper (26), we showed that an acylpeptide K-26 inhibited the flagellar movement of the Triton-extracted sea urchin sperm but neither the sliding between outer doublets nor the axonemal ATPase activity was suppressed. It was speculated that K-26 affects the regulatory system for production or propagation of bending waves. In the present study, we investigated the targets for K-26 to get an insight into the regulatory mechanism of the flagellar movement. We found that the inhibition of flagellar movement by K-26 was canceled by the addition of a Triton X100 -soluble fraction in a cAMP-dependent manner, that the factor contained in the Triton-soluble fraction coincided with the cAMP-dependent protein kinase (cA kinase), and that the kinase activity was inhibited by K-26.

\section{MATERIALS AND METHODS}

Materials. The following biochemicals were purchased: ATP from Yamasa Shoyu Co., Tokyo, cAMP, histone IIA and beef heart cA-kinase from Sigma Chem. Co., St Louis, MO., U.S.A., $\gamma^{32}$ P ATP from ICN Radiochem. Irvine, CA., U.S.A.

Preparation of Triton $X$-100-soluble fraction. Spermatozoa were obtained from a sea urchin Anthocidaris crassispina by the injection of $0.5 \mathrm{M} \mathrm{KCl}$ or $2 \mathrm{mM}$ acetylcholine $\cdot \mathrm{Cl}$ into the body cavity, and were stored as "dry" sperm on ice, which was used within $10 \mathrm{~h}$. Fifty $\mu \mathrm{l}$ of the "dry" sperm was added to $950 \mu$ l of a membrane extraction medium (see Materials AND METHODs in the preceding paper, 26) and suspended in an Eppendorf tube at room temperature. After $2 \mathrm{~min}$, it was centrifuged at $10,000 \times \mathrm{g}$ for $5 \mathrm{~min}$ at room temperature (19$23^{\circ} \mathrm{C}$ ). The supernate was used as the Triton-soluble fraction.

Incorporation of Pi into the Triton-extracted sperm. The "dry" sperm were diluted with $4 \mathrm{vol}$ of chilled filtrated sea water (FSW) to make a stock sperm suspension. Ten $\mu \mathrm{l}$ of this suspension was added to $490 \mu$ l of the membrane extraction medium, and gently swirled at room temperature. After $1 \mathrm{~min}, 10 \mu \mathrm{l}$ of the extracted sperm suspension was added to $80 \mu \mathrm{l}$ of a reactivation medium (see MATERIALS AND METHODs in the preceding paper, 26) devoid of both ATP and polyethylene glycol (PEG), either in the absence or in the presence of $14 \mu \mathrm{M}$ K-26. Reactivation was started by the addition of $\gamma^{32} \mathrm{P}$ ATP at a final concentration of $0.1 \mathrm{mM}(4 \mu \mathrm{Ci})$. After the desired time, $15 \mu \mathrm{l}$ of this suspension was taken out and quickly mixed with $5 \mu \mathrm{l}$ of $5 \%(\mathrm{w} / \mathrm{v})$ bovine serum albumin on parafilm on ice. This suspension was immediately applied onto a glass filter (Whatman GF/C) and ice cold 5\% (w/v) trichloroacetic acid (TCA) was dropped onto it. The glass filter was then transferred into a beaker that contained ice cold $5 \%$ TCA $(5-10 \mathrm{ml} /$ glass filter) and kept for $30 \mathrm{~min}$ on ice. After the TCA was discarded, fresh 5\% TCA solution was added and the beaker was kept in boiling water for $10 \mathrm{~min}$. The glass filter was then washed in 5\% TCA for $10 \mathrm{~min}$ at room temperature, and the wash procedure repeated three times. After three more washes with ethanol, the glass filter was dried on a hot plate and placed in a glass vial with $5 \mathrm{ml}$ toluene scintillator containing $5 \mathrm{~g} \mathrm{2,5-diphenyloxazole} \mathrm{(DPO)} \mathrm{and} 0.25 \mathrm{~g} \mathrm{1,} \mathrm{4-bis-[2-(5-phenylox-}$ azolyl)] benzene (POPOP) in 1 liter toluene, and the radioactivity was measured with a scintillation counter (Beckman LS8000 system, Beckman Inst. Inc., CA, U.S.A.).

Preparation of the factor in the Triton-soluble fraction. Unless otherwise mentioned, the preparation was performed at $0-4^{\circ} \mathrm{C}$. The "dry" sperm were suspended in $15 \mathrm{vol}$ of a solution of $0.08 \%$ Triton X-100, $0.15 \mathrm{M} \mathrm{KCl}, 2 \mathrm{mM} \mathrm{MgSO}{ }_{4}, 0.5 \mathrm{mM}$ EDTA, $1 \mathrm{mM} \mathrm{CaCl}, 0.5 \mathrm{mM}$ dithiothreitol (DTT), $0.2 \mathrm{mM}$ phenylmethylsulfonyl fluoride (PMSF), $10 \mu \mathrm{g} / \mathrm{ml}$ leupeptin 
and $10 \mathrm{mM}$ 3-( $\mathrm{N}$-morpholino) propanesulfonic acid (MOPS)- $\mathrm{NaOH}$ (pH 7.2) and extracted for $10 \mathrm{~min}$. The suspension was then centrifuged at $12,000 \mathrm{xg}$ for $10 \mathrm{~min}$. The resulting supernatant was further centrifuged at $100,000 \times \mathrm{g}$ for $30 \mathrm{~min}$, and chromatographed on a hydroxylapatite column pre-equilibrated with the extraction medium devoid of Triton X-100. After the column was thoroughly washed with the equilibration medium to remove Triton $\mathrm{X}$ 100 , the adsorbed meterials were eluted with a linear concentration gradient of potassium phosphate buffer ( $\mathrm{pH}$ 7.2) from 0 to $0.35 \mathrm{M}$. The fractions possessing the activity to cancel the inhibition of the motility of the Triton-extracted sperm by K-26 were dialyzed against $50 \mathrm{mM} \mathrm{KCl}, 2 \mathrm{mM} \mathrm{MgSO}, 0.2 \mathrm{mM}$ ethyleneglycol bis-( $\beta$-aminoethylether)- $\mathrm{N}, \mathrm{N}, \mathrm{N}^{\prime}, \mathrm{N}^{\prime}$ tetraacetic acid (EGTA), $0.3 \mathrm{mM}$ DTT, $0.2 \mathrm{mM}$ PMSF and $10 \mathrm{mM}$ Tris- $\mathrm{HCl}$ (pH 8.0) and further chromatographed on a DEAE-cellulose column pre-equilibrated with the dialysis solution. After washes with the same solution, adsorbed materials were eluted with a linear $\mathrm{KCl}$ gradient from 0.05 to $0.5 \mathrm{M}$ dissolved in the dialysis solution.

Assays for the activities of the factor and of $c A$ kinase. The fractions obtained from hydroxylapatite and DEAE-cellulose column chromatographies were dialyzed against $0.15 \mathrm{M}$ $\mathrm{KCl}, 2 \mathrm{mM} \mathrm{MgSO}_{4}, 0.2 \mathrm{mM}$ EGTA, $0.3 \mathrm{mM}$ DTT, $0.2 \mathrm{mM}$ PMSF and $10 \mathrm{mM}$ Tris- $\mathrm{HCl}$ (pH 8.0). The motility of the Triton-extracted sperm was assayed in the presence of the dialyzed fraction, $0.1 \mathrm{mM}$ cAMP and $6 \mu \mathrm{M} \mathrm{K}-26$, the activity of the factor to cancel the inhibition of the motility of the Triton-extracted sperm by K-26 was defined as \% motility observed under these conditions. The activity of cAMP-dependent protein kinase was assayed in $0.15 \mathrm{M} \mathrm{KCl}, 2 \mathrm{mM} \mathrm{MgSO}, 0.2 \mathrm{mM}$ EGTA, $1 \mathrm{mg} / \mathrm{ml}$ histone IIA, $1 \mathrm{mM} \gamma^{32} \mathrm{P}$ ATP $(0.2 \mu \mathrm{Ci})$

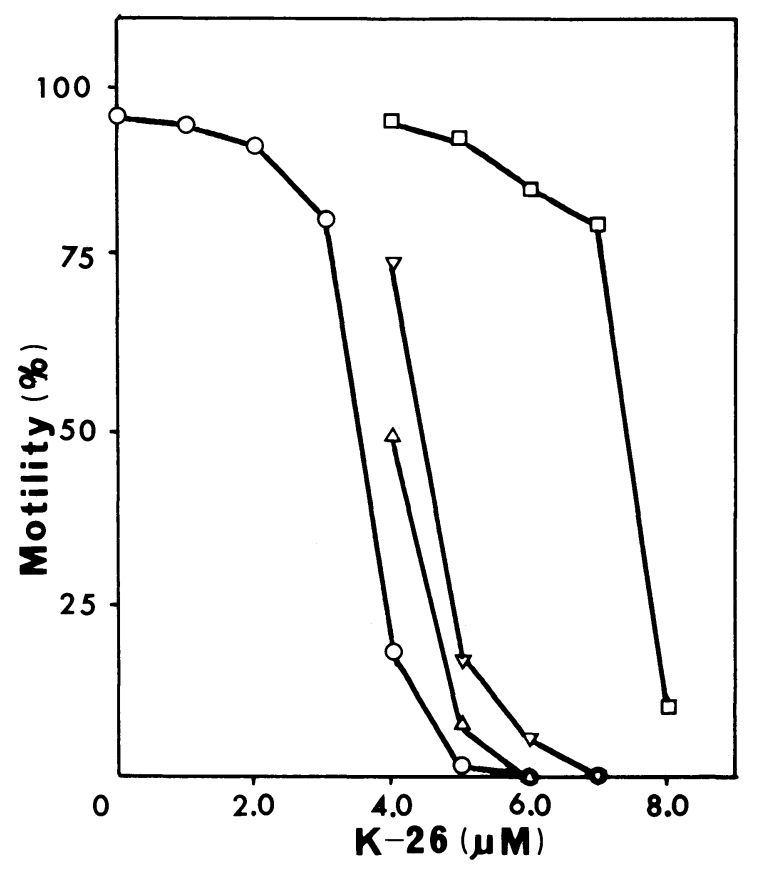

Fig. 1. Effects of cAMP and Triton-soluble fraction on the inhibition of the motility by K-26. The concentration of K-26 in the reactivation medium was varied and \% motility was assayed as described in Materials AND Methods. $\bigcirc$, No addition. $\triangle, 0.1 \mathrm{mM}$ cAMP was added. $\nabla$, Triton-soluble fraction was added (final $18 \mu \mathrm{g}$ protein $/ \mathrm{ml}$ ). $\square$, Both Triton-soluble fraction and $0.1 \mathrm{mM}$ cAMP were added. 
and $10 \mathrm{mM}$ Tris- $\mathrm{HCl}(\mathrm{pH} 8.0)$ either in the presence or in the absence of $0.1 \mathrm{mM}$ cAMP at room temperature. The amount of $\mathrm{Pi}$ incorporated into histone was measured by the same method as described above except that bovine serum albumin was not used.

Others. Triton-extracted sperm models were prepared and \% motility was measured according to the methods described in the preceding paper (26). Protein concentration was determined by the method of Lowry et al. (14) or by Bradford (2), using bovine serum albumin as a standard.

\section{RESULTS}

Effect of cAMP and Triton-soluble fraction on the motility of Triton-extracted sperm in the presence of $K-26$. In the presence of 5-7 $\mu \mathrm{M} \mathrm{K}-26$, the motility of the Triton-extracted sperm was suppressed and this inhibition could not be reversed by dilution to reduce the concentration of K-26, as described in the preceding paper (26). However, the motility was restored up to a level observed in the absence of $\mathrm{K}$ 26 by the addition of both $0.1 \mathrm{mM}$ cAMP and Triton-soluble fraction to the reactivation medium (Fig. 1). On the other hand, addition of either cAMP or the Triton-soluble fraction alone did not restore the motility significantly. At $4 \mu \mathrm{M} \mathrm{K}$ 26, the addition of either cAMP or the Triton-soluble fraction alone restored the motility to $49.5 \%$ or $74.0 \%$, respectively. On the other hand, the inhibition of the motility by $8 \mu \mathrm{M}$ K-26 could not be restored by the addition of both cAMP and the

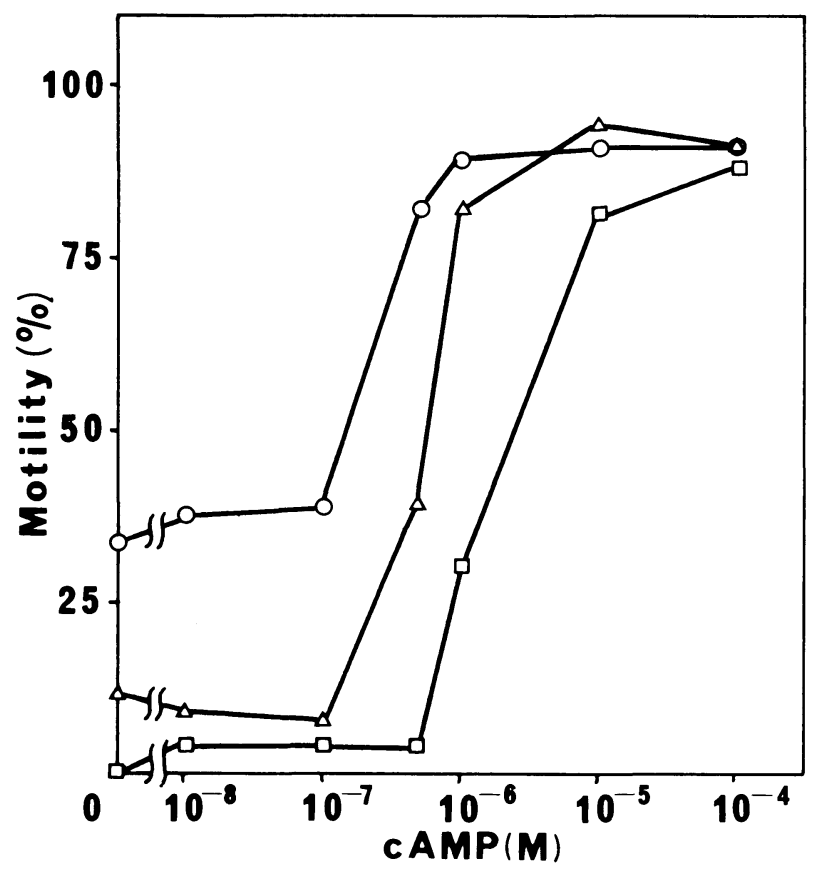

Fig. 2. Effect of cAMP concentration on the restoration of motility by Triton-soluble fraction. The concentration of cAMP in the reactivation medium was varied and \% motility was measured in the presence of the Triton-soluble fraction $(18 \mu \mathrm{g}$ protein $/ \mathrm{ml})$. The concentration of $\mathrm{K}-26$ in the reactivation medium was $4 \mu \mathrm{M}(\bigcirc), 5 \mu \mathrm{M}(\triangle)$ or $7 \mu \mathrm{M}(\square)$. 
Triton-soluble fraction.

Fig. 2 shows the effect of the concentration of cAMP added to the reactivation medium. In the absence of cAMP, $\%$ motility was very low even in the presence of the Triton-soluble fraction. As the concentration of cAMP increased, the $\%$ motility in the presence of 4 or $5 \mu \mathrm{M} \mathrm{K}-26$ increased and reached plateau levels at about $1 \mu \mathrm{M}$ cAMP. In the presence of $7 \mu \mathrm{M} \mathrm{K}-26$, more cAMP was required to restore the motility.

Effect of $K-26$ on the incorporation of $P$ into the Triton-extracted sperm. Fig. 3 shows the time course of incorporation of $\mathrm{Pi}$ into the Triton-extracted sperm either in the absence or in the presence of $14 \mu \mathrm{M} \mathrm{K}-26$. For this experiment, the concentration of the Triton-extracted sperm in the reactivation medium was increased to 20 times that used in the motility assay, and the concentration of ATP was decreased to $0.1 \mathrm{mM}$ in order to obtain a higher specific radioactivity. Under these conditions, the concentration of K-26 that was required to obtain the complete inhibition of the motility increased to $14 \mu \mathrm{M}$. In the absence of $\mathrm{K}-26, \mathrm{Pi}$ incorporated into the Triton-extracted sperm seemed to increase with time until $1.5 \mathrm{~min}$, and decrease after $2 \mathrm{~min}$. On the other hand, incorporation of $\mathrm{Pi}$ in the presence of $14 \mu \mathrm{M} \mathrm{K}-26$

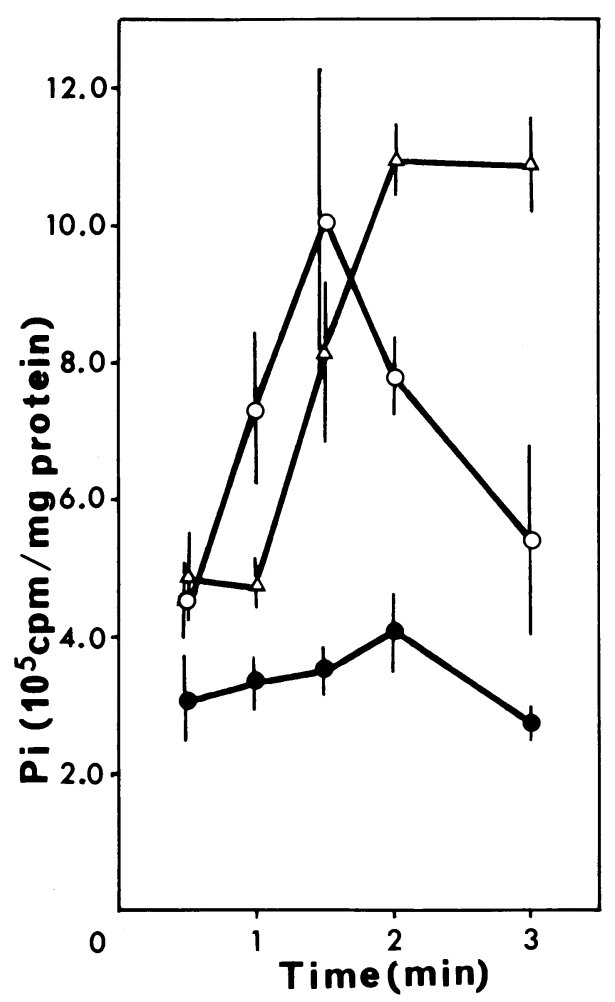

Fig. 3. Time course of Pi incorporation into the Triton-extracted sperm. The amount of Pi incorporated into the Triton-extracted sperm was measured as described in Materials and MEthods. $\bigcirc$, No K-26. $\bullet, 14 \mu \mathrm{M} \mathrm{K}-26 . \triangle, 10 \mu \mathrm{M}$ cAMP and DEAE-cellulose fraction No. $16(50 \mu \mathrm{g} / \mathrm{ml})$ shown in Fig. 5 were added in the presence of $14 \mu \mathrm{M} \mathrm{K}-26$. Each point is the average obtained from three measurements. Vertical bars represent the standard deviations. 


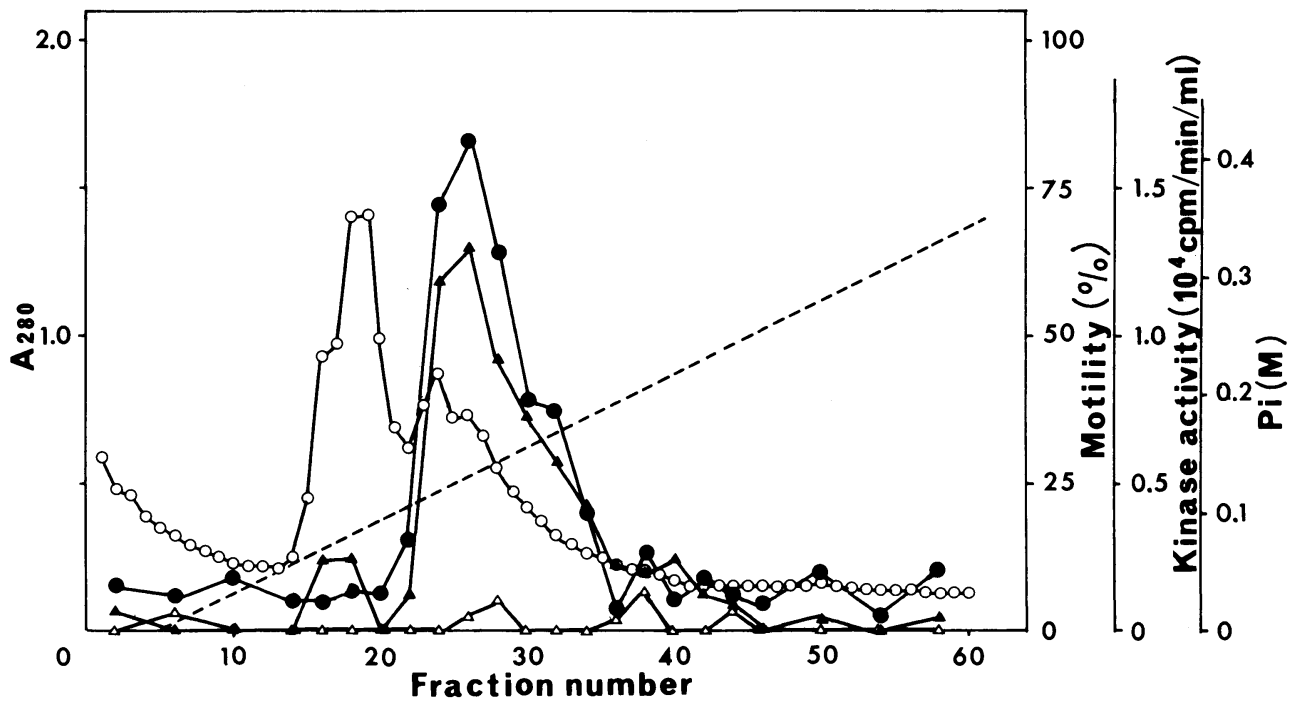

Fig. 4. Hydroxylapatite column chromatography of Triton-soluble fraction. The activity of factor $(\bullet)$ was assayed as described in MATERIALS AND MEthods. The activity of cA kinase was assayed in the presence $(\Delta)$ or in the absence $(\triangle)$ of $0.1 \mathrm{mM}$ cAMP, and the amount of Pi incorporated into histone was measured as described in MATERIALS AND Methods. Dashed line represents the concentration of potassium phosphate buffer. $\mathrm{O}$; A280.

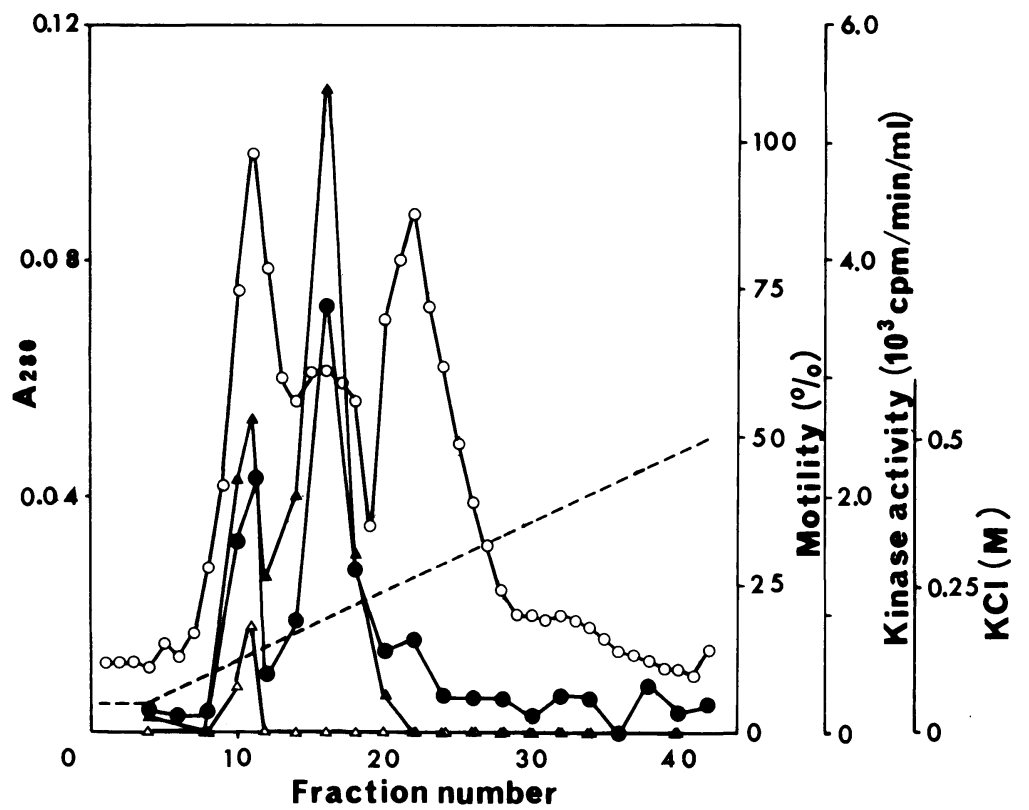

Fig. 5. DEAE-cellulose column chromatography of hydroxylapatite column fractions. Dashed line represents $\mathrm{KCl}$ concentration. For other symbols see the legend to Fig. 4. 
was lower than that in the absence of K-26 and did not change with time.

Partial purification of active factors in the Triton soluble fraction. The above results indicate that K-26 affected cA kinase, thereby inhibiting the motility of the Triton-extracted sperm. To confirm this possibility, we tried to purify the factor(s) in the Triton-soluble fraction which were able to cancel the inhibitory effect of $\mathrm{K}$ 26 , and then investigated the relationships between the factor(s) and cA kinase. Fig. 4 shows a hydroxylapatite column chromatography of the Triton-soluble fraction. A single peak of the activity that could restore the motility in the presence of $6 \mu \mathrm{M}$ $\mathrm{K}-26$, was detected at the position of $0.13 \mathrm{M} \mathrm{Pi}$. This peak coincided with that of $\mathrm{cA}$ kinase. The fractions 24-32 were pooled and further chromatographed on a DEAEcellulose column (Fig. 5). Two activity peaks were detected; a small peak at $0.12 \mathrm{M}$ $\mathrm{KCl}$ and a large peak at $0.2 \mathrm{M} \mathrm{KCl}$. These peaks coincided precisely with the $\mathrm{cA}$ kinase activity peaks.

The extent of recovery of the motility that was suppressed by K-26 was dependent on the concentration of the DEAE-cellulose fraction (fraction 16 in Fig. 5) added to the reactivation medium (Fig. 6). The concentration of $\mathrm{K}-26$, which gave a half maximal inhibition of the motility, was increased when the amount of the DEAEcellulose fraction was increased. Furthermore, the addition of the DEAE-cellulose fraction with cAMP restored the incorporation of $\mathrm{Pi}$ into the Triton-extracted sperm in the presence of $14 \mu \mathrm{M} \mathrm{K}-26$ (Fig. 3). Also the motility inhibited by K-26 was restored completely. In this case, no decrease in the amount of $\mathrm{Pi}$ incorporated into the Triton-extracted sperm was observed during the incubation. When either cAMP or the DEAE-cellulose fraction alone was added to the reactivation medium, neither the motility nor incorporation of $\mathrm{Pi}$ was restored at all (data not shown).

Effect of $K-26$ on the activity of $c A$ kinase. The cAMP-dependent cA kinase ac-

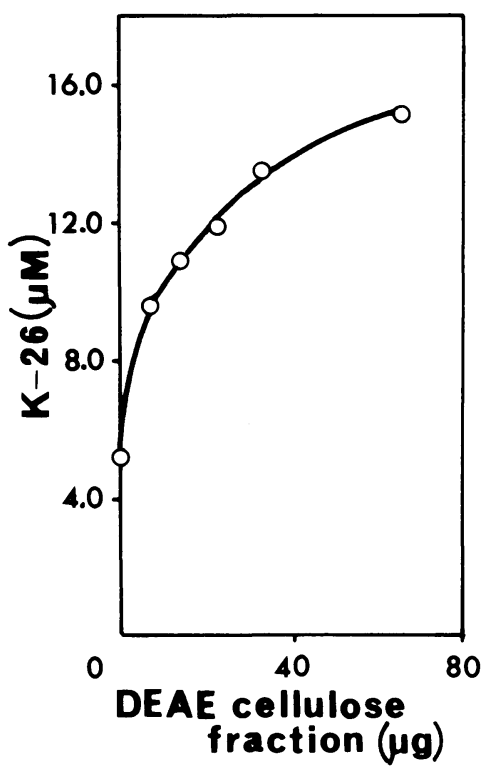

Fig. 6. Effect of concentration of $\mathrm{cA}$ kinase fraction on the $\mathrm{K}-26$ concentration that was required to obtain $50 \%$ inhibition of the motility. The reactivation medium contained $10 \mu \mathrm{M}$ cAMP. DEAEcellulose fraction No. 16 shown in Fig. 5 was used as the cA kinase fraction. 


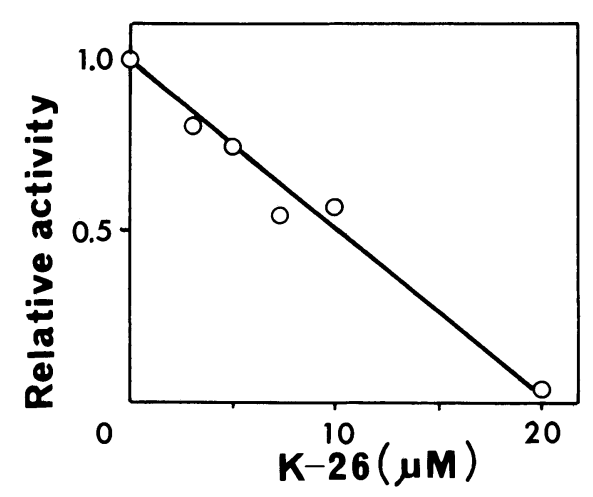

Fig. 7. Effect of K-26 on the activity of cA kinase fraction. DEAE-cellulose fraction No. 16 shown in Fig. $5(20 \mu \mathrm{g} / \mathrm{ml})$ was used as the cA kinase fraction. The amount of Pi incorporated into histone was measured as described in Materials and Methods. The concentration of cAMP was $10 \mu \mathrm{M}$.

tivity of the DEAE-cellulose column fraction 16 shown in Fig. 5 was suppressed by K-26 (Fig. 7). The K-26 concentration which gave a half maximal inhibition of the cA kinase activity was $10 \mu \mathrm{M}$, which was a little higher than that required to inhibit the motility of the Triton-extracted sperm (see Fig. 6 of the preceding paper, 26). A similar results was obtained for fraction 11, shown in Fig. 5 as a small peak of cA kinase (data not shown). In addition, the activity of cA-kinase from beef heart was also inhibited by K-26 with a half maximal inhibition at $20 \mu \mathrm{M}$ (data not shown).

\section{DISCUSSION}

Acylpeptide K-26 is an effective inhibitor of the flagellar movement of Triton-extracted sperm. This inhibitory effect is suggested to be caused by the suppression of the cAMP-dependent protein phosphorylation, by the following observations. 1) The suppression of the flagellar movement by K-26 was canceled by the addition of both cAMP and the Triton-soluble fraction of sperm. The active factor(s) in the Triton-soluble fraction co-eluted with cA kinase(s) in two different column chromatographies. 2) The incorporation of Pi into the Triton-extracted sperm was also suppressed by K-26 at the same concentration at which the inhibition of the motility was observed. The incorporation of Pi that was suppressed by K-26 was restored by the addition of cAMP and DEAE-cellulose fractions. 3) K-26 inhibited the activity of cA kinase that was contained in the Triton-soluble fraction of sperm.

A heat stable inhibitory protein of the cA kinase has been found in various tissues. This protein has been known to act on the kinase by binding to the catalytic subunit in a competitive manner with the protein substrate $(1,7,24)$. Recently, a digested peptide of the inhibitory protein that retained the activity of the original inhibitor, was prepared (5) and peptides that corresponded to the active site of the inhibitor were synthesized (6). However, the amino acid sequence of K-26 was completely distinct from that of the inhibitor peptides. On the other hand, cAMP was required for the cancellation of the inhibitory effect of K-26 on the motility. Thus, it may be that K-26 affected the regulatory subunit of protein kinase in a cAMP-sensitive manner.

In some animal species, such as trout (15), tunicate (17) and bull (13), the motility 
of the Triton-extracted sperm is reported to be initiated or enhanced by the cAMPdependent phosphorylation. A protein factor prepared from a detergent-extract of sea urchin or starfish sperm was shown to be phosphorylated by cA-kinase and to be able to reactivate the motility of Triton-extracted models prepared from aged sperm (11). A similar protein factor called axokinin has been found in mammalian sperm and shown to induce the flagellar movement of Triton-extracted sperm $(22,23)$. Furthermore, dephosphorylation in the Triton-extracted sea urchin sperm catalyzed by a phosphoprotein phosphatase from bovine cardiac muscle, was shown to reduce the motility of the Triton-extracted sperm (21). From these observations, it is suggested that the cAMP-dependent phosphorylation is important for activation or initiation of flagellar motility. This idea is also supported by the present study on sea urchin sperm.

When added to the swimming Triton-extracted sea urchin sperm, K-26 caused cessation of the flagellar movement. A similar result was obtained by the use of $\mathrm{H}-8$ (10), an inhibitor of cA kinase (9). Therefore it is suggested that the cAMP-dependent phosphorylation in the Triton-extracted sperm plays an important role not only in the initiation but also in the maintenance of the flagellar motility.

Recently, Brokaw (4) reported effects of protein phosphatase or lithium on the flagellar movement of Triton-extracted sperm of a tunicate (Ciona) and a sea urchin (Lytechinus pictus). Both agents caused an asymmetrical bending wave form in which the oscillatory bend formation occurred in the basal part of the flagellum, but the bend was damped during its propagation and the beat frequency was decreased. Further exposure lead to quiescence. In the case of $\mathrm{K}-26$, beat frequency was decreased (previous paper, 26) and the bending wave form became asymmetrical, but the form was different from that observed in the lithium or protein phosphatase-induced inhibition: that is, the bend produced near the head was not damped and the bend angle increased (25). However, since the species of sea urchin used in Brokaw's and our studies are different, it may be premature to discuss the differences in the results obtained. It remains to be clarified how the cAMP-dependent phosphorylation participates in the mechanism which controls oscillation or propagation of flagellar bending wave.

Acknowledgments. We thank Dr. Yoshihiro Ozeki (University of Tokyo) for advice on Pi incorporation measurements. We also thank Dr. Akiya Hino (Nagoya University) for his valuable discussion.

\section{REFERENCES}

1. AshBY, C.D. and D.A. WALSH. Characterization of the interaction of a protein inhibitor with adenosine 3', 5'-monophosphate-dependent protein kinase. J. Biol. Chem. 248, 1255-1261, 1973

2. BRADFORD, M.M. A rapid and sensitive method for the protein quantitation of microgram quantities of protein utilizing the principle of protein-dye binding. Anal. Biochem. 72, 248-254, 1976

3. BroKaw, C.J., R. JossLin and L. Bobrow. Calcium ion regulation of flagellar beat symmetry in reactivated sea urchin spermatozoa. Biochem. Biophys. Res. Commun. 58, 795-800, 1974

4. BROKAw, C.J. A lithium sensitive regulator of sperm flagellar oscillation is activated by cAMPdependent phosphorylation. J. Cell Biol. 105, 1789-1798, 1987

5. Cheng, H.-C., S.M. Van Patten, A.J. Smith and D.A. Walsh. An active twenty-amino-acidresidue peptide derived from the inhibitor protein of the cyclic AMP-dependent protein kinase. Biochem. J. 231, 655-661, 1985

6. Cheng, H.-C., B.H. Kemp, R.B. Pearson, A.J. Smith, L.Misconi, S.M. Van Patten and D.A. WALSH. A potent synthetic peptide inhibitor of the cAMP-dependent protein kinase. J. Biol. Chem. 261, 989-992, 1986 
7. Demaille, J.G., K.A. Peters and E.H. Fischer. Isolation and properties of the rabbit skeletal muscle protein inhibitor of adenosine 3', 5'-monophosphate dependent protein kinase. Biochemistry 16, 3080-3086, 1977

8. GibBons, B.H. and I.R. Gibbons. Calcium-induced quiescence in reactivated sea urchin sperm. $J$. Cell Biol. 84, 13-27, 1980

9. HidAKa, H., M. INAGAKI, S. KaWAmoto and Y. SASAKI. Isoquinolinesulfonamides, novel and potent inhibitors of cyclic nucleotide dependent protein kinase and protein kinase C. Biochemistry 23 , 5036-5041, 1984

10. Hino, A., R. Kawachi, H. Sasaki and S. TAKahashi. Adenosine 3', 5'-monophosphate-dependent protein kinase and its endogenous substrates in sea urchin sperm. Cell Struct. Funct. 11, 511, 1986 (Abst. 39th Ann. Meet. Japan Soc. Cell Biol.)

11. Ishiguro, K., H. MURofUSH and H. SAKaI. Evidence that cAMP-dependent protein kinase and a protein factor are involved in reactivation of Triton X-100 models of sea urchin and starfish spermatozoa. J. Cell Biol. 92, 777-782, 1982

12. Katada, J., C. Shingyoji and K. Takahashi. Analysis of $\mathrm{Ca}^{2+}$-dependent flagellar responses of sea urchin spermatozoa by iontophoretic applications of $\mathrm{Ca}^{2+}$ and of ATP. Cell Struct. Funct. 11, 510, 1986 (Abst. 39th Ann. Meet. Japan Soc. Cell Biol.)

13. Lindeman, C.B. A cAMP-induced increase in the motility of demembranated bull sperm models. Cell 13, 9-18, 1978

14. Lowry, O.H., N.J. Rosebrough, A.L. FarR and R.J. Randall. Protein measurement with the Folin phenol reagent. J. Biol. Chem. 193, 265-275, 1951

15. Morisawa, M. and M. Oxuno. Cyclic AMP induces maturation of trout sperm axoneme to intiate motility. Nature 295, 703-704, 1982

16. Murofushi, H., K. Ishiguro, D. Takahashi, J. IKeda and H. Sakai. Regulation of sperm flagellar movement by protein phosphorylation and dephosphorylation. Cell Motil. Cytoskeleton 6, 83-88, 1986

17. OPRESKo, L.K. and C.J. Brokaw. cAMP-dependent phosphorylation associated with activation of motility of Ciona sperm flagella. Gamete Res. 8, 201-218, 1983

18. SAtir, P. Studies on cilia. III. Further studies on the cilium tip and "sliding filament" model of ciliary motility. J. Cell Biol. 39, 77-94, 1968

19. Shingyoj, C., A. Murakami and K. TAKahashi. Local reactivation of Triton-extracted flagella by iontophoretic application of ATP. Nature 265, 269-270, 1977

20. Summers, K.E. and I.R. GibBons. Adenosine triphosphate-induced sliding of tubules in trypsintreated flagella of sea urchin sperm. Proc. Natl. Acad. Sci. U.S.A. 68, 3092-3096, 1971

21. Takahashi, D., H. Murofushi, K. Ishiguro, J. Ikeda and H. Sakai. Phosphoprotein phosphatase inhibits flagellar movement of Triton models of sea urchin spermatozoa. Cell Struct. Funct. 10, 327-337, 1985

22. TASH, J.S., S.S. KAKAR and A.R. Means. Flagellar motility requires the cAMP-dependent phosphorylation of a heat stable NP-40-soluble $56 \mathrm{kd}$ protein, axokinin. Cell 38, 551-559, 1984

23. TASH, J.S., H. Hidaka and A.R. Means. Axokinin phosphorylation by cAMP-dependent protein kinase is sufficient for activation of sperm flagellar motility. J. Cell Biol. 103, 649-655, 1986

24. Whitehouse, S., J.R. Feramisco, J.E. Casenellie, E.G. Krebs and D.A. Walsh. Studies on the kinetic mechanism of the catalytic subunit of the cAMP-dependent protein kinase. J. Biol. Chem. 258, 3693-3701, 1983

25. Yokota, E., I. Mabuchi, A. Kobayashi and H. Sato. Effects of acylpeptide K-26 on the Tritonextracted sperm model. II. Cell Struct. Funct. 13, 684, 1988 (Abst. 41th Ann. Meet. Japan Soc. Cell Biol.)

26. Yokota, E., I. Mabuchi, A. KobaYashi and H. Sato. Effects of acylpeptide K-26 on the motility of sea urchin sperm model. I. Inhibition of the motility of both live and Triton X-100-extracted sperm. Cell Struct. Funct. 14, 299-310, 1989 